Document downloaded from:

http://hdl.handle.net/10251/103726

This paper must be cited as:

Pascual, L.; Cerqueira, C.; García-Fernández, A.; De Luis-Fernández, B.; Soares, E.; Souza, M.; Missailidis, S... (2017). MUC1 aptamer-capped mesoporous silica nanoparticles for controlled drug delivery and radio-imaging applications. Nanomedicine Nanotechnology Biology and Medicine. 13(8):2495-2505. doi:10.1016/j.nano.2017.08.006

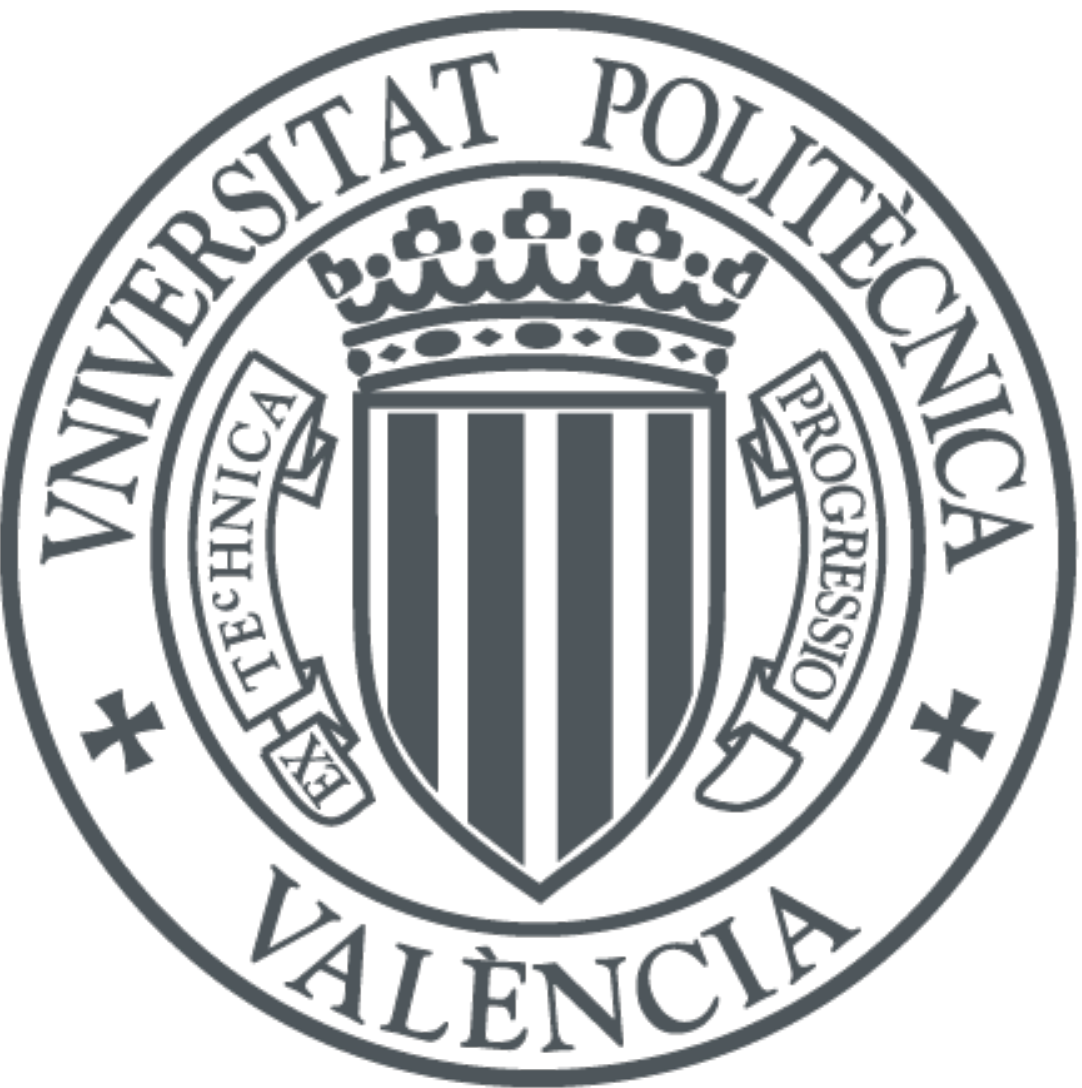

The final publication is available at

http://dx.doi.org/10.1016/j.nano.2017.08.006

Copyright Elsevier

Additional Information 


\section{MUC1 aptamer-capped mesoporous silica nanoparticles for controlled drug delivery and radio-imaging}

applications

Lluis Pascual, ${ }^{\mathrm{a}, \mathrm{b}, \mathrm{c}, \mathrm{d},+}$ Cristal Cerqueira-Coutinho, ${ }^{\mathrm{e}}$ Alba García-Fernández, ${ }^{\mathrm{a}, \mathrm{b}, \mathrm{c}, \mathrm{d},+}$ Beatriz de

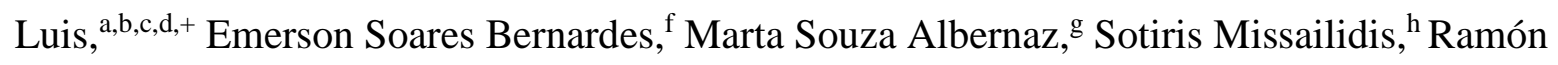
Martínez-Máñez, *,a,b,c,d Ralph Santos-Oliveira,*,g, Mar Orzaez, d.i and Félix Sancenón, ${ }^{\text {a,b,c,d }}$

a Instituto Interuniversitario de Investigación de Reconocimiento Molecular y Desarrollo Tecnológico (IDM). Universitat Politècnica de València, Universitat de València, Spain.

b Departamento de Química, Universitat Politècnica de València, Camino de Vera s/n, 46022, Valencia, Spain.

c CIBER de Bioingeniería, Biomateriales y Nanomedicina (CIBER-BBN).

d Unidad Mixta UPV-CIPF de Investigación en Mecanismos de Enfermedades y Nanomedicina, Universitat Politècnica de València, Centro de Investigación Príncipe Felipe, Valencia, Spain.

${ }^{\mathrm{e}}$ Federal University of Rio de Janeiro, Faculty of Pharmacy, Rio de Janeiro-Brazil

${ }^{\mathrm{f}}$ Centro de Radiofarmácia, Instituto de Pesquisas Energéticas e Nucleares, São Paulo, Brazil g Brazilian Nuclear Energy Commission, Nuclear Engineering Institute, Rio de Janeiro, Brazil

h Oswaldo Cruz Foundation, Biomanguinhos, Rio de Janeiro, Brazil

${ }^{\mathrm{i}}$ Centro de Investigación Príncipe Felipe. Eduardo Primo Yúfera, 3. Valencia 46012, Spain.

+ These authors contributed equally to this work.

Word count for Abstract: 148

Word count for manuscript:

Number of references: 58

Number of figures: 8

Number of tables: 1

Number of Supplementary online-only files, if any: 1

Financial support information: Financial support from the Spanish Government and FEDER funds (Project MAT2015-64139-C4-1) and the Generalitat Valenciana (Project PROMETEOII/2014/047) is gratefully acknowledged. 


\section{ABSTRACT}

Mucin 1 (MUC1) is a cell surface protein overexpressed in breast cancer. Mesoporous silica nanoparticles (MSNs) loaded with safranin O, functionalized with aminopropyl groups and gated with the negatively charged MUC1 aptamer have been prepared (S1-apMUC1) for specific targeting and cargo release in tumoral versus non-tumoral cells. Confocal microscopy studies showed that the S1-apMUC1 nanoparticles were internalized in MDA-MB-231 breast cancer cells that overexpress MUC1 receptor with subsequent pore opening and cargo release. Interestingly, the MCF-10-A non-tumorigenic breast epithelial cell line that do not overexpress MUC1, showed reduced (S1-apMUC1) internalization. Negligible internalization was also found for S1-ap nanoparticles that contained a scrambled DNA sequence as gatekeeper. S2apMUC1 nanoparticles (similar to S1-apMUC1 but loaded with doxorubicin) internalized in MDA-MB-231 cells and induced a remarkable reduction in cell viability. Moreover, S1apMUC1 nanoparticles radio-labeled with ${ }^{99 \mathrm{~m}}$ Tc (S1-apMUC1-Tc) showed a remarkable tumor targeting in in vivo studies with MDA-MB-231 tumor-bearing Balb/c mice.

\section{KEYWORDS}

Radiopharmaceuticals, nanotechnology, oncology, mesoporous silica nanoparticles.

\section{BACKGROUND}

Nanotechnology offers myriads of possibilities of developing innovative materials with extended applications in almost countless scientific and technological fields. ${ }^{1}$ Perhaps one of the most promising applications of nanotechnology, in the form of smart nanomaterials, is related with nanomedicine., ${ }^{2,3}$ Among the realm of nanodispositives with powerful applications in medicine, those related with controlled release are among the most appealing. The possibility of 
supplying certain drugs or active molecules and biomolecules into the site at which its action is required is expected to drastically reduce side effects. ${ }^{4}$ In order to achieve this task, drugs or bioactive agents are normally incorporated into nanomaterials. ${ }^{5}$ Moreover, these loaded nanocarriers can also be functionalized with targeting ligands that allow selective internalization in the cells in which their action is required. ${ }^{6}$

Among the set of nanocarriers, mesoporous silica nanoparticles (MSNs) have been extensively used in recent years due to their remarkable properties, such as homogeneous pore size, large specific volume and area, good thermal stability, biocompatibility and easy functionalization. ${ }^{7,8}$ Notwithstanding, perhaps the most appealing feature of MSNs as carriers is the possibility of functionalizing them with molecular/supramolecular ensembles on their external surface to develop gated materials, which ideally show "zero delivery", yet release the payload oncommand in response to specific external stimuli. A number of gated MSNs able to deliver the payload with $\mathrm{pH}$ changes, redox reactions, light, magnetic fields, ultrasounds, temperature, polarity changes and presence of molecules or biomolecules have been recently described. ${ }^{9}$ These gated materials have been mainly studied as drug delivery systems and for sensing and diagnostic applications. ${ }^{9-20}$ Among biomolecules, DNA and aptamers have been recently used as caps to develop gated materials for drug delivery and sensing. ${ }^{21-25}$ Moreover, certain aptamers can be used as targeting agents, which make them a valuable alternative to antibodies and peptides. ${ }^{26,27}$

From another point of view, one of the most powerful in vivo imaging techniques is isotopic labeling. ${ }^{28}$ This technique consists in marking the (bio)-molecule or nanodevice that we wish to track with selected radionuclides. Decay in the radionuclide emits radiation that can be detected by signaling the presence of the labeled system. In nuclear medicine, a widely used technique to 
detect radionuclides is single photon emission computed tomography (SPECT). ${ }^{29,30}$ Among various SPECT radionuclides, ${ }^{99 \mathrm{~m}} \mathrm{Tc}$ has been extensively used to develop radiopharmaceuticals because of its ideal nuclear properties and easy low-cost availability. ${ }^{31-33}$ Recently certain SPECT radionuclides $\left({ }^{99 \mathrm{~m}} \mathrm{Tc}\right.$ and ${ }^{188} \mathrm{Re}$ ) have been incorporated into specific aptamers and evaluated for their clinical applicability. ${ }^{34-36}$ Some of those radionuclide-labeled aptamer probes have shown rapid accumulation rates in tumor, good targeting ability and fast clearance from blood. MSNs have also been radiolabeled with several radioisotopes by different approaches (e.g., direct adsorption onto surfaces, coating nanoparticles with poly(ethylene glycol) conjugated with marked antibodies, functionalizing the nanoparticle surface with $t$-cyclooctene derivatives that have undergone $3+2$ cycloadditions with labeled tetraazines and grafting complexes through amidation reactions) and have been used for positron emission tomography (PET) and SPECT imaging. ${ }^{37-45}$ However, a typical drawback of some of these labeled systems is poor tumor accumulation..$^{39,40}$

MUC1 is a mucin glycoprotein expressed in the extracellular matrix by most glandular and ductal epithelial cells, and by several hematopoietic cell lineages. ${ }^{46}$ MUC1 is also highly expressed by the majority of human adenocarcinomas and its presence has been associated with poor clinical prognosis. MUC1 is shed in the bloodstream of adenocarcinoma patients and is the antigen in commercial serum tumor marker assays. ${ }^{47}$ The extracellular presentation of MUC1, its elongated structure and characteristic under-glycosylation patterns allow the protein core to be exposed in cancer cells, which thus make it a suitable target for immunotherapeutic and targeted radiotherapy approaches. ${ }^{48}$ In line with this, MUC1 aptamers (that bind ligands to the MUC1 glycoprotein tumor marker) have been functionalized with commercially available chelators, radiolabeled with ${ }^{99 \mathrm{~m}}$ Tc and used in bio-distribution and imaging studies in xenografted MCF-7 
tumor-bearing mice. ${ }^{49-51}$ MUC1 aptamers have also been grafted onto the external surface of silica nanoparticles labeled with fluorophores and the prepared nanodevices used to detect breast cancer cells. $^{52}$

Taking into account this information and based in our interest in preparing gated MSNs and applying them to controlled release and signaling applications, ${ }^{9,11}$ we show herein the synthesis, characterization, controlled release features and imaging properties of MSNs loaded with safranin O or with doxorubicin, capped with an aptamer targeting MUC1 glycoprotein. These nanoparticles released the entrapped dye/drug in the presence of DNAse I enzyme and were preferentially internalized by MDA-MB-231 (expresses glycoprotein MUC1 in the membrane) cancer cells. Moreover, ${ }^{99 \mathrm{~m}}$ Tc radiolabeled capped nanoparticles, injected into MDA-MB-231 tumor-bearing Balb/c mice, showed remarkable accumulation in tumors in SPECT images. The same accumulation trend was observed in bio-distribution studies.

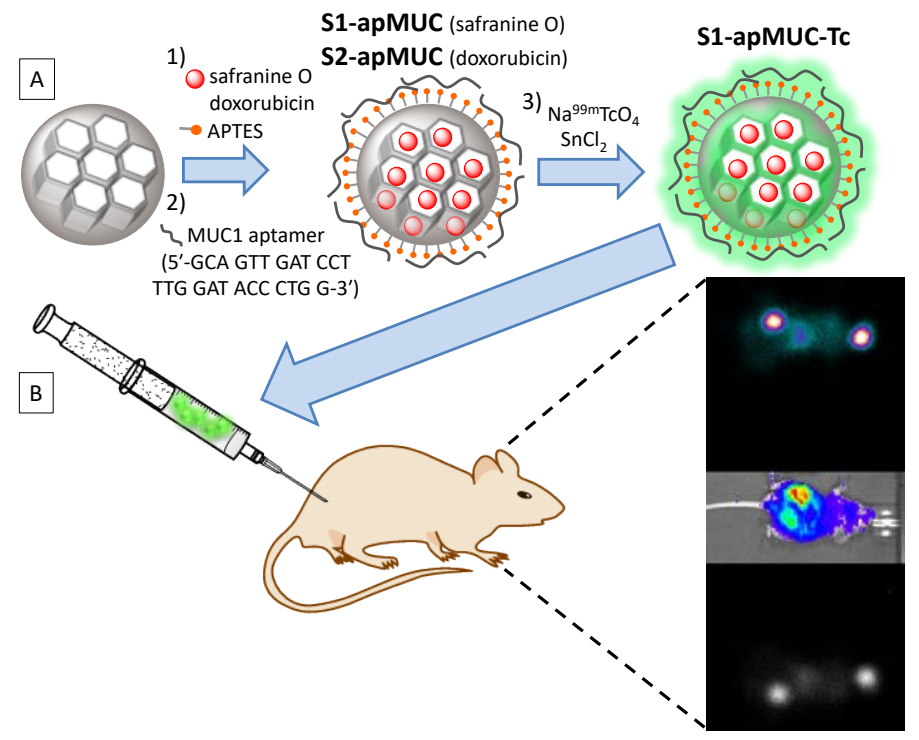

Figure 1. (A) Synthetic route used to prepare S1-apMUC1, S2-apMUC1 and S1-apMUC1-Tc nanoparticles. (B) Application of S1-apMUC1-Tc as a radiolabeling tool. 


\section{MATERIALS AND METHODS}

Tumour xenograft models

MDA-MB-231 cells (American Type Culture Collection, Manassas, VALLC) were cultured in RPMI (Gibco, Life technologies, MD, USA), supplemented with $10 \%$ of fetal bovine serum (Gibco, Life technologies, MD, USA) and $50 \mu \mathrm{g} / \mathrm{mL}$ of gentamicin (Gibco, Life technologies, MD, USA). Mycoplasma contamination in cultured cells was excluded using the Lonza Mycoplasma detection kit. Tumors were established by a subcutaneous injection of $2 \times 10^{6}$ MDA-MB-231 cells on the backs of 6-week-old female Balb/c nude mice. Tumor size was monitored for 3 weeks and measured by a caliper. Tumor size before imaging was about $2 \mathrm{~cm}$. Balb/c nude mice were bred at the animal facility of the Nuclear Energy Research Institute (IPEN). All the experiments complied with relevant laws and were approved by local animal ethics committees. Mice were observed 3 times a week to evidence any distress, ascites, paralysis or excessive weight loss.

Cell culture studies

Cells MDA-MB-231 were cultured in DMEM/F12 containing 10\% FCS, $100 \mathrm{U} / \mathrm{mL}$ of penicillin and streptomycin, and MCF-10-A in and DMEM/F12 containing $100 \mathrm{U} / \mathrm{mL}$ of penicillin and streptomycin, 10\% FCS, $10 \mu \mathrm{g} / \mathrm{mL}$ of insulin solution human recombinant from Saccharomyces cerevisiae, $0.5 \mu \mathrm{g} / \mathrm{mL}$ of hydrocortisone, $100 \mathrm{ng} / \mathrm{mL}$ of Cholera toxin from Vibrio cholerae and $20 \mathrm{ng} / \mathrm{mL}$ of EGF recombinant human protein solution.

Cell viability studies 
The toxicological profile of the S1-apMUC1 solid was studied in vitro in MDA-MB-231 and MCF-10-A cell lines. MDA-MB-231 and MCF-10-A were seeded in a 96-well plate and treated with different S1-apMUC1 concentrations (0, 25, 50, 100 and $200 \mu \mathrm{g} / \mathrm{mL}$ in PBS). Cells were incubated for 24 and $48 \mathrm{~h}$ and the viability was determined adding the cell proliferation reagent WST-1 and for 1h. Finally, cell viability was measured at $595 \mathrm{~nm}$ in the Wallac Workstation.

\section{Cellular uptake studies}

To study the capacity of the S1-apMUC1 to internalize into the MDA-MB-231 cells, uptake studies were carried out. For this purpose, a solid containing covalently attached rhodamine and capped with the MUC1 aptamer was prepared (S-RhB-apMUC1) and internalization studies were performed by confocal microscopy with lysosome markers. MDA-MB-231 cells were seeded over glass coverslips at 300.000 cells/ml in 6-well assays plates and incubated at $37{ }^{\circ} \mathrm{C}$. The S-RhB-apMUC1 nanoparticles were added to cells at $50 \mu \mathrm{g} / \mathrm{mL}$, lysotracker green DND-26 was added at $0.2 \mu \mathrm{M}$, and cells were incubated for $1 \mathrm{~h}$ at $37^{\circ} \mathrm{C}$. Then cells were washed several times with PBS. DNA marker, Hoechst 33342, was added at $1 \mu \mathrm{g} / \mathrm{mL}$. Slides were visualized using a confocal microscope Leica TCS SP8 HyVolution II

Controlled release of solid S1-apMUC1 triggered by the presence of MUC1 in cell lines Internalization and cargo delivery from S1-apMUC1 in MDA-MB-231 (that expressed high levels of MUC1) and MCF-10-A (that expressed low levels of MUC1) cells were studied by confocal microscopy. Both cells lines were seeded over glass coverslips at a cell density of 250,000 cells/ml in 6-well assay plates and incubated at $37{ }^{\circ} \mathrm{C}$. The S1-apMUC1 nanoparticles were added to cells (100 $\mu \mathrm{g} / \mathrm{mL})$ and were incubated at $37{ }^{\circ} \mathrm{C}$ for $1 \mathrm{~h}$. Then cells were washed 
several times with PBS. Finally, DNA marker Hoechst 33342 was added. Slides were visualized using a confocal microscope Leica TCS SP2 AOBS. Moreover, to further prove the specific S1apMUC1 nanoparticles MUC1-mediated cell uptake, experiments with a solid capped with a scrambled DNA sequence without any selectivity towards MUC1 receptor (solid S1-Ap) were performed. MDA-MB-231 cells were treated with S1-ap at $100 \mu \mathrm{g} / \mathrm{ml}$. After $1 \mathrm{~h}$ of incubation, cells were washed with PBS and slides were prepared for confocal microscopy as described above.

\section{Anti-tumoral activity of S2-apMUC1}

In order to evaluate the effectiveness of MUC1-capped nanoparticles as drug delivery system, a solid loaded with doxorubicin (S2-apMUC1) was prepared. MDA-MB-231 and MCF-10-A cells were seeded in 96-well plate. Then, S2-apMUC1 solid was added at 50 and $100 \mu \mathrm{g} / \mathrm{mL}$. After 30 min of incubation, cells were washed with PBS and new media added in each case and incubated for another $24 \mathrm{~h}$. Doxorubicin-induced cell death was evaluated by adding the WST-1 reagent for $1 \mathrm{~h}$ and absorbance was measured at $595 \mathrm{~nm}$.

\section{Bioluminescence and imaging}

Three female Balb/c nude mice aged 8-9 weeks with breast cancer in the right flank were used for bio-distribution and imaging (SPECT). The animals inducted with breast cancer were examined by bio-luminesce. Mice were administered D-luciferin (150 mg/kg, Promega) by intraperitoneal injection. Immediately after the D-luciferin injection, photons from each animal's whole body were counted by the IVIS Spectrum imaging system (Xenogen/Caliper Life Sciences, CA) according to the manufacturer`s instructions. Data were analyzed by the Living 
Image 4.3 software (Xenogen). Planar images were obtained 90 min after injecting the S1apMUC1-Tc nanoparticles (3.7 MBq in $0.2 \mathrm{~mL}$ ) with a Millennium Gamma Camera (GE Healthcare, Cleveland, USA). Counts were acquired for $5 \mathrm{~min}$ in a $15 \%$ window centered at 140 $\mathrm{KeV}$. Images were processed using the OsiriX software, and regions of interest (ROIs) over the tumor were selected for specific analyses. Three inducted mice were imaged separately.

\section{Bio-distribution}

Mice were maintained at a controlled temperature $\left(23^{\circ} \mathrm{C} \pm 2\right)$ with water and food ad libitum. No sedative or anesthetic was used. Labeled samples (3.7 MBq/0.2 mL) were administered by intraocular (retro-orbital) injection. Mice were sacrificed by asphyxiation in a carbon dioxide gas chamber 120 min after administering the S1-apMUC1-Tc nanoparticles. Organs (brain, lungs, kidneys, stomach, small and large intestine, bladder, heart and blood pool) were removed, weighed, and the activity in each organ and blood was counted by a gamma counter (Perkin Elmer Wizard ${ }^{\circledR} 2470$ ). The results were expressed as a percentage of the injected dose per organ. The Institutional Review Board and the Animal Ethics Committee approved the study protocol (number 23076.020578/2013-07).

\section{RESULTS}

Design and synthesis of aptamer-capped nanoparticles

MSNs were prepared in alkaline media following well-known procedures using $n$ cetyltrimethylammonium bromide (CTAB) as directing agent to condense the inorganic precursor tetraethylortosilicate (TEOS).$^{53}$ The obtained powder was washed and CTAB was removed by calcination. The pores of the calcined MSNs were loaded with safranin O and the external surface of the nanoparticles was functionalized with (3-aminopropyl) triethoxysilane 
(solid S1). Aminopropyl moieties were positively charged at a neutral $\mathrm{pH}$ and they are known to display electrostatic and hydrogen bonding interactions with negatively charged aptamers. Therefore, the addition of an MUC1 aptamer to a suspension of S1 nanoparticles resulted in pore capping, which yielded the final material S1-apMUC1 (see Figure 1). The same procedure described above, but using doxorubicin instead of safranin $\mathrm{O}$ as cargo, was used for the preparation of S2 and S2-apMUC1 nanoparticles (see also Figure 1). S1-apMUC1 and S2apMUC1 nanoparticles were expected to be effectively internalized by cancer cells that overexpressed glycoprotein MUC1 and to deliver the cargo via the hydrolysis of the capping aptamer by DNAse enzymes. Moreover, we also labeled S1-apMUC1 with the ${ }^{99 \mathrm{~m}} \mathrm{Tc}$ radioisotope to explore the potential use of these nanoparticles as radiopharmaceutical probe (S1apMUC1-Tc).

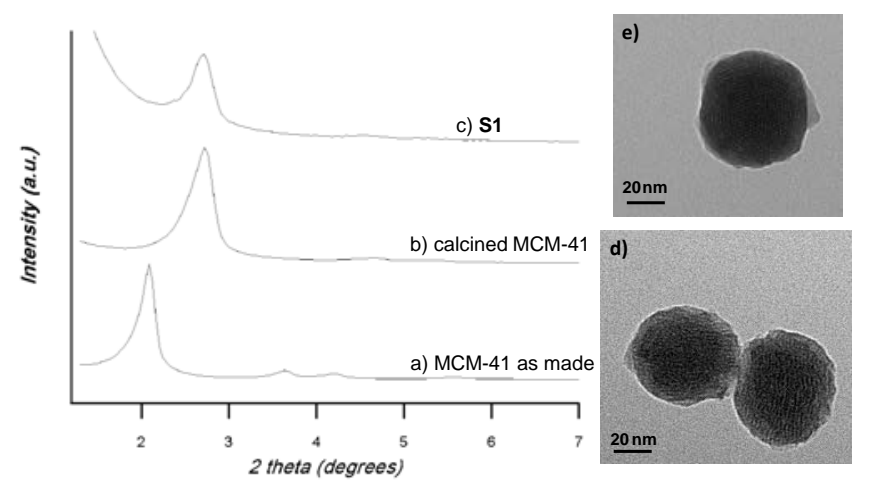

Figure 2. Left: Powder X-ray diffraction patterns of MCM-41 nanoparticles as made (a), calcined MCM-41 nanoparticles (b) and solid S1 (c). Right: TEM images of the calcined MCM41 nanoparticles (d) and solid S1 (e).

Characterization of gated MSNs 
The powder X-ray diffraction (PXRD) of the MCM-41 as-synthesized nanoparticles (curve a in Figure 2) showed four low-angle reflections, typical of a hexagonal mesoporous array that can be indexed as (100), (110), (200) and (210) Bragg peaks. The presence of the (100) reflection in the calcined MSNs (curve b in Figure 2) and in solid S1 (curve c in Figure 2) evidenced that the loading pores with safranin $\mathrm{O}$ and the further functionalization of the external surface with aminopropyl moieties did not modify the 3D mesoporous structure. Furthermore, the mesoporous structure was confirmed by transmission electron microscopy (TEM) in MSNs and S1 samples (Figure 2). TEM images also showed that the starting MSNs and solid S1 consisted of spherical particles with a diameter of ca. $100 \mathrm{~nm}$. Dynamic light scattering measurements resulted in values of hydrodynamic diameters of $114 \mathrm{~nm}$ and $407 \mathrm{~nm}$ for the starting calcined MSNs and S1-apMUC1, respectively. Moreover, zeta potential values of $-11.90,+3.02$ and $7.92 \mathrm{mV}$ were obtained for the calcined MSNs, S1 and S1-apMUC1.

$\mathrm{N}_{2}$ adsorption-desorption studies on the starting MSNs and S1 were carried out. For both materials, the pore volume was calculated by applying the Barret-Joyner-Halenda (BJH) ${ }^{54}$ model on the adsorption branch of the isotherm and the total specific surface was calculated by the Brunauer-Emmet-Teller (BET) ${ }^{55}$ model. The values obtained for the staring calcined MSNs and S1 are listed in Table 1. Moreover, the safranin O and aminopropyl contents on solid S1 were determined by thermogravimetric studies and elemental analyses, which amounted to 0.044 (loading efficiency of 5.5\%) and $1.821 \mathrm{mmol} \mathrm{g}^{-1}$, respectively.

Table 1. BET-specific surface values, pore volumes and pore sizes calculated from the $\mathrm{N}_{2}$ adsorption-desorption isotherms for calcined MSNs and S1.

\begin{tabular}{lllllll}
\hline Solid & $\mathrm{S}_{\mathrm{BET}}\left[\mathrm{m}^{2} \mathrm{~g}^{-1}\right]$ & $\begin{array}{l}\text { BJH } \\
{[\mathrm{nm}]}\end{array}$ & pore & size $\left.^{[\mathrm{a}, \mathrm{b}]}\right]$ & $\begin{array}{l}\text { Total pore } \\
{\left[\mathrm{cm}^{3} \mathrm{~g}^{-1}\right]}\end{array}$ & volume $^{[\mathrm{a}]}$ \\
\hline
\end{tabular}




\begin{tabular}{llll}
\hline Calcined MSNs & 1195 & 2.51 & 0.961 \\
S1 & 66 & - & 0.036 \\
\hline
\end{tabular}

[a] Pore volumes and pore sizes related only to interparticle mesopores.

[b] Pore sizes estimated by the BJH model applied to the adsorption branch of the isotherm.

Energy dispersive X-ray spectroscopy (EDX, $20 \mathrm{kV}$ ) studies on S1-apMUC1 showed the presence of phosphorus atoms (values of weight and the atom percentage of 0.36 and $0.19 \%$ respectively, see Supporting Information), which is in agreement with the capping of the nanoparticles with the MUC1 aptamer.

In vitro safranin O release studies form S1-apMUC1

Cargo release from the S1-apMUC1 nanoparticles alone and in the presence of DNAse I was studied. In a typical experiment, $100 \mu \mathrm{g}$ of S1-apMUC1 were suspended in Tris buffer (20 mM Tris, $\mathrm{pH} 7.5 ; 37.5 \mathrm{mM} \mathrm{MgCl}_{2}$ ) and then separated into two aliquots. Only to one of the samples

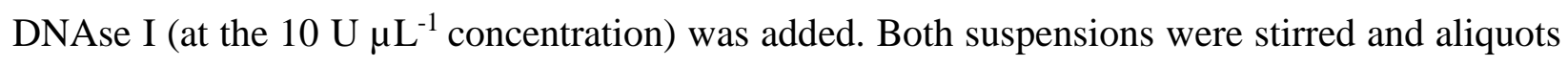
were taken at scheduled times. These aliquots were centrifuged to remove the solid and the emission of the safranin $\mathrm{O}$ released at $585 \mathrm{~nm}$ (excitation at $520 \mathrm{~nm}$ ) was measured. The obtained release profiles are shown in Figure 3. 


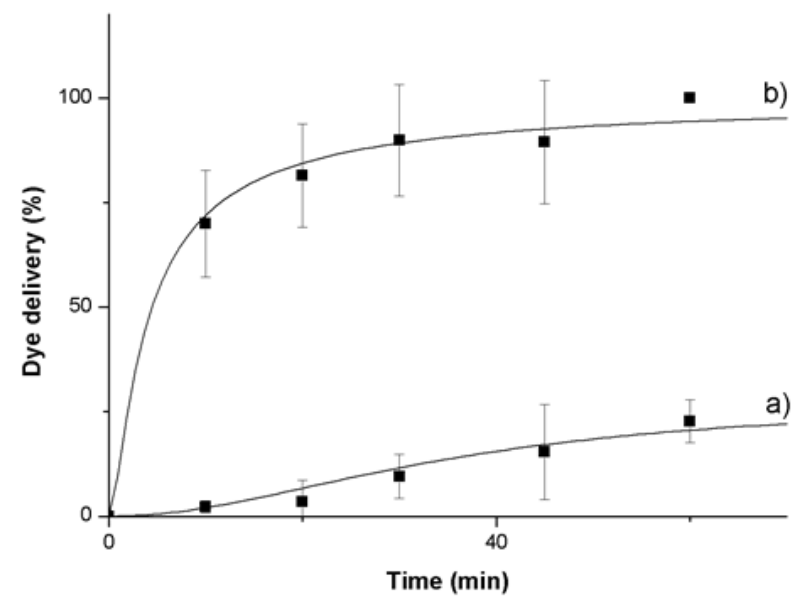

Figure 3. In vitro release profiles of safranin O from solid S1-apMUC in the absence (a) and presence (b) of DNAse I in Tris (20 mM pH 7.5) that contained $\mathrm{MgCl}_{2}$ (37.5 mM).

Cell viability studies

In order to discard any toxicity associated with the mesoporous scaffold or the MUC1 coating shell, cell viability assays using S1-apMUC1 nanoparticles at different concentrations were evaluated by the WST-1 assay (see Supporting Information). The results demonstrated that S1apMUC1 nanoparticles were well-tolerated by MDA-MB-231 and MCF-10-A cell lines at concentrations up to $200 \mu \mathrm{g} / \mathrm{mL}$ after 24 and $48 \mathrm{~h}$ of exposure.

\section{Cellular uptake studies}

Uptake studies with cells were carried out with nanoparticles S-RhB-apMUC1, which are similar to S1-apMUC1 but containing rhodamine B covalently anchored through the formation of thiourea bonds to the silica surface. Internalization studies in MDA-MB-231 cells were analysed by confocal microscopy (Figure 4). 
Lysotracker green DND-26

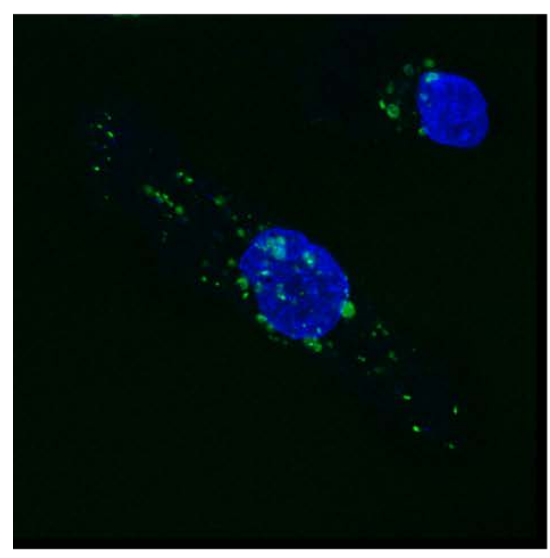

Rhodamine B

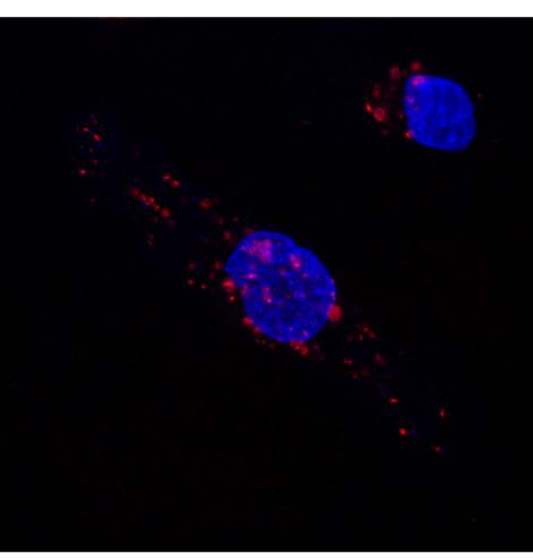

Merge

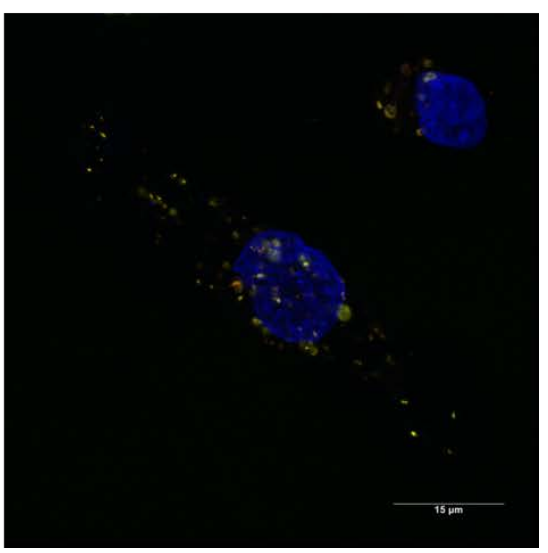

Figure 4. Internalization studies of S-RhB-apMUC1 in MDA-MB-231 cells. Cells were incubated for $1 \mathrm{~h}$ in the presence of S-RhB-apMUC1 solid (50 $\mu \mathrm{g} / \mathrm{mL})$ and lysosomes were marked with lysotracker green DND-26 $(0.2 \mu \mathrm{M})$. The internalization of the nanoparticles was followed by rhodamine B fluorescence (red) in the presence of the lysosome probe Lysotracker green DND-26 (green) and DNA probe Hoechst 33342 (blue). The presence of a yellow signal in the merged image evidences a high co-localization of the S-RhB-apMUC1 nanoparticles and the lysosomes.

Controlled release performance of solid S1-apMUC1 in cell lines

The controlled cargo release from S1-apMUC1 nanoparticles in cells was assessed by confocal microscopy studies. The MDA-MB-231 and MCF-10-A cell lines were incubated with the S1-apMUC1 nanoparticles for $1 \mathrm{~h}$ and safranin O-associated fluorescence was measured (see Figure 5A and C respectively). Results show a significantly higher release of safranin in MDAMB-231 tumor cells, which overexpress MUC1, versus non-tumor MCF-10-A cells.

Moreover, the MUC1-mediated specific uptake of the S1-apMUC1 nanoparticles was also assessed using solid S1-ap, loaded with safranin O, but capped with a scrambled DNA sequence 
(with no binding specificity with MUC1). MDA-MB-231 cells were treated with S1-ap and after $1 \mathrm{~h}$ of incubation the internalization was followed by safranin O-associated fluorescence (see Figure 5B). Quantification of the fluorescence associated with safranin $\mathrm{O}$ was determined for each treatment to confirm the results observed in the confocal images (Figure 5D). 

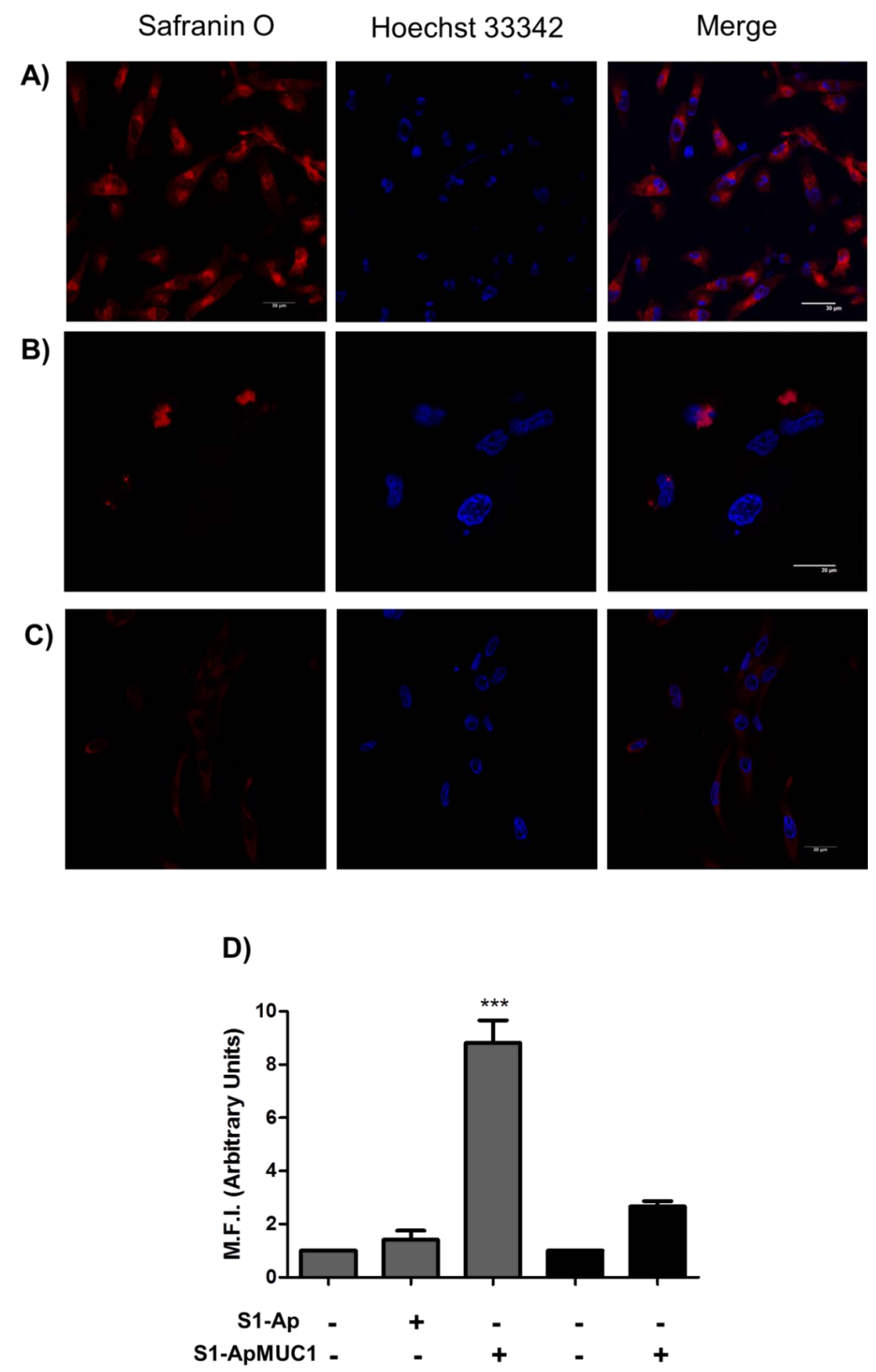
Figure 5. Specific targeting of S1-apMUC1. Cellular uptake of S1-apMUC1 A) and S1-ap B) in the MDA-MB-231 cells. C) cellular uptake of S1-apMUC1 in MCF-10-A cells. Both cell lines were incubated for $1 \mathrm{~h}$ in the presence of S1-apMUC1 $(100 \mu \mathrm{g} / \mathrm{mL})(\mathrm{A}$ and C) and S1-ap (100 $\mu \mathrm{g} / \mathrm{mL}$ ) (B). The internalization of the nanoparticles was followed by safranin O-associated fluorescence (red) in the presence of DNA marker Hoechst 33342 (blue). D) Quantification of the safranin O-associated fluorescence intensity for the different treatments. Quantification in MDA-MB-231 cells (grey bars) in the presence or absence of S1-ap and S1-apMUC1 nanoparticles. In black bars quantification of safranin O associated fluorescence in MFC-10-A cells in the absence or presence of S1-apMUC1 nanoparticles. Three independent experiments were done, which gave similar results. Data are expressed as mean $\pm \mathrm{s}$. Statistically significant differences were found among the different treatments in the case of MDA-MB-231 in the presence of S1-apMUC1 nanoparticles when paired t Student tests were applied ( $\mathrm{p}<0.0001)$.

\section{Anti-tumoral assays with S2-apMUC1}

In order to demonstrate the potential applicability of the MUC1 capped nanoparticles for drug delivery, a new material based on MSNs loaded with doxorubicin and capped with the MUC1 aptamer (S2-apMUC1) was prepared. MDA-MB-231 and MCF-10-A cells were treated with 50 and $100 \mu \mathrm{g} / \mathrm{mL}$ of S2-apMUC1 and cell viability assays were carried out (Figure 6). Release of the doxorubicin cargo induced cell death at nanoparticle concentrations where S1-apMUC1 was innocuous. Moreover, the cell death induction capability of S2-apMUC1 in the tumor cell line MDA-MB-231 was significantly higher than in the non tumoral MCF-10-A. 


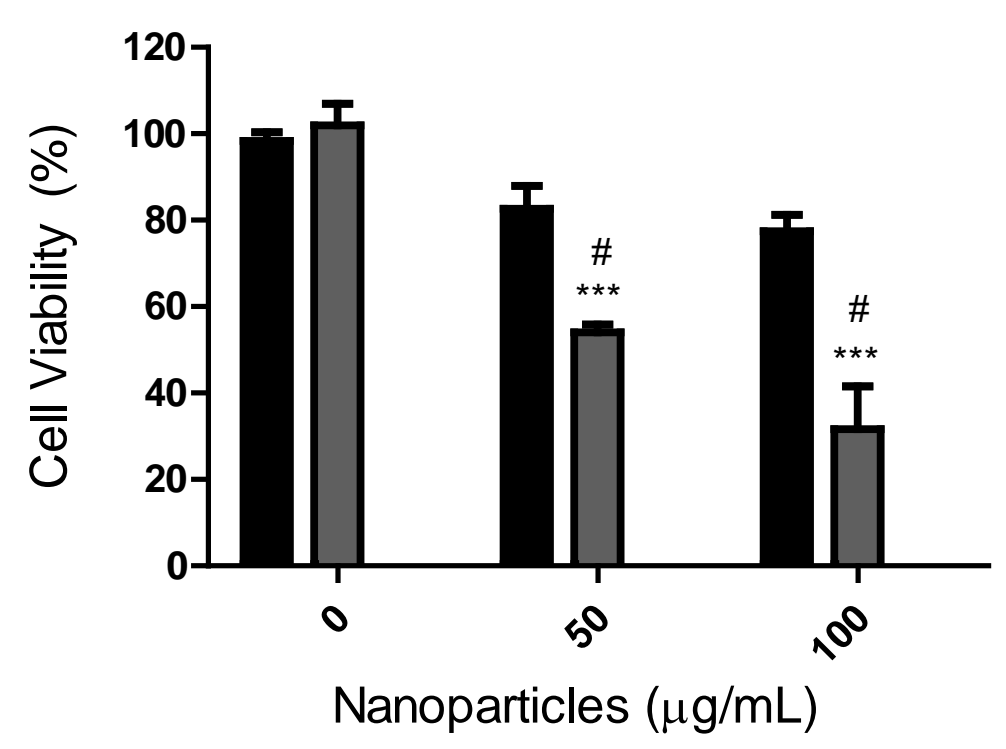

Figure 6. S2-apMUC1 induces cell death in breast cancer cells. Cell viability assays of S2apMUC1 nanoparticles in MDA-MB-231 (gray) and MCF-10-A (black) cells. S2-apMUC1 nanoparticles were added at 50 and $100 \mu \mathrm{g} / \mathrm{ml}$ and, after $30 \mathrm{~min}$ of incubation, cells were washed with PBS and new media added in each case and incubated for another $24 \mathrm{~h}$. Then, doxorubicin activity was evaluated by adding the WST-1 reagent for $1 \mathrm{~h}$ and absorbance was measured at 595 $\mathrm{nm}$. Three independent experiments were done, which gave similar results. Data are expressed as mean $\pm \mathrm{s}$. Statistically significant differences were found among the different treatments when paired t Student tests were applied ( $\mathrm{p}$ < 0.0001) between the MDA-MB-231 treated at 50 and 100 $\mu \mathrm{g} / \mathrm{ml}$ with S2-apMUC1 nanoparticles and the untreated cells (\#), and significant differences were found among the treatments between MDA-MB-231 and MCF-10-A cells (***).

\section{Radiolabeling and imaging studies}

In order to take a step forward and to impart the MUC1 capped nanoparticles with diagnostic features, we carried out the labelling of S1-apMUC1 with the ${ }^{99 \mathrm{~m}} \mathrm{Tc}$ radioisotope. ${ }^{99 \mathrm{~m}} \mathrm{Tc}$ is a 
metastable isomer of ${ }^{99} \mathrm{Tc}$ used as a radioactive tracer in diagnostic nuclear medicine procedures. It emits easily detectable $140.51 \mathrm{keV}$ gamma rays and has a half-life of $6.02 \mathrm{~h}^{56}$

In a typical procedure, S1-apMUC1 $(150 \mu g)$ were incubated with $\mathrm{SnCl}_{2}$ as the reducing agent and with $\mathrm{Na}^{99 \mathrm{~m}} \mathrm{TcO}_{4}(300 \mu \mathrm{L}$ with $100 \mu \mathrm{Ci}$ ) for $20 \mathrm{~min}$ at room temperature. This resulted in the production of ${ }^{99 \mathrm{~m}}$ Tc that labeled the nanoparticles (S1-apMUC1-Tc). The small quantity of the prepared labeled solid precluded complete characterization by standard techniques. Nevertheless, the correct radiolabeling of MSNs was assessed by thin layer chromatography (TLC) using acetone as the mobile phase (see Supporting Information).

The labeled S1-apMUC1-Tc nanoparticles were tested for in vivo imaging using SPECT. For this purpose, a 6-week-old female MDA-MB-231 tumor-bearing Balb/c mice model was used. S1-apMUC1-Tc (3.7 MBq/0.2 mL) was administered to mice by intraocular (retro-orbital) injection. In vivo static planar images were obtained with a Millennium Gamma Camera after 90 min in a window centered at $140 \mathrm{keV}$. The obtained images are shown in Figure 7. As seen in Figures 7A and 7C, the MUC1-positive tumor region showed strong signals (white spots) due to the accumulation of S1-apMUC1-Tc nanoparticles at 90 min post-injection. Besides, SPECT images of the organs and tumor excised from the S1-apMUC1-Tc treated mice after $120 \mathrm{~min}$ post-injection were taken (see Supporting Information). Strong signals were observed in kidneys, liver and tumor indicating the preferential accumulation of S1-apMUC1-Tc nanoparticles into these organs. 


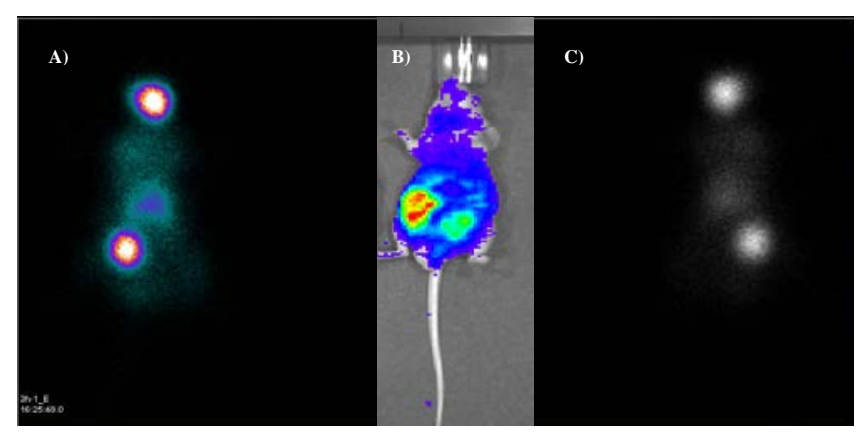

Figure 7. A) Static planar SPECT image of the MDA-MB-231 tumor-bearing Balb/c mice model after administering the S1-apMUC1-Tc nanoparticles (3.7 MBq/0.2 mL) at 90 min postinjection. B) Bioluminescence images from mice on day 21 after the intra-ventricular injection of the MDA-MB-231 cancer cells that reveal tumoral lesions. C) Static planar SPECT inverse image of the MDA-MB-231 tumor-bearing Balb/c mice model after administering the S1apMUC1-Tc nanoparticles (3.7 MBq/0.2 mL) at 90 min post-injection.

Bio-distribution assays

For the bio-distribution assays, mice were sacrificed $120 \mathrm{~min}$ after the injection of S1apMUC1-Tc, organs were removed, weighed and activity was counted with a gamma counter. The results obtained as a percentage of injected dose per gram and per organ are shown in Figure 8A and 8B respectively. The same experiments were carried out with bare MSNs labelled with ${ }^{99 m}$ Tc in healthy and MDA-MB-231 tumor-bearing Balb/c mice as negative and positive controls respectively (see Supporting Information). 

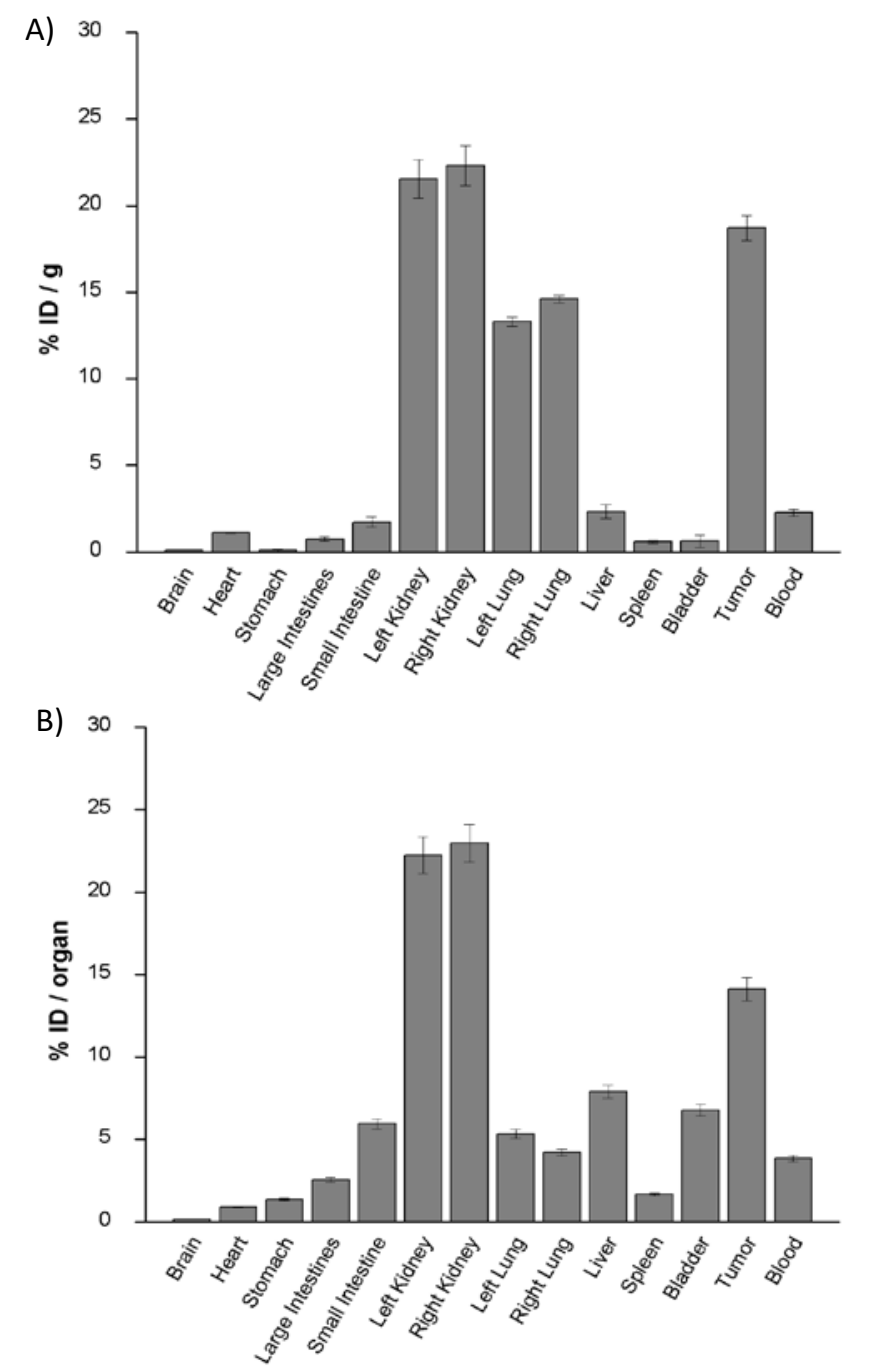

Figure 8. Bio-distribution profile of the S1-apMUC1-Tc nanoparticles in MDA-MB-231 tumorbearing Balb/c mice ( $\mathrm{n}=3$ ) expressed as $(A)$ dose per gram of organ, $(B)$ dose per organ.

\section{DISCUSSION}

PXRD of S1 evidenced that the process of loading the pores with safranin $\mathrm{O}$ and the functionalization of the external surface with aminopropyl groups did not modify the 3D mesoporous structure (Figure 2). Besides, TEM images of the calcined MSNs and S1 
nanoparticles confirmed the presence of the mesoporous structure (Figure 2). The typical channels of the mesoporous silica network were visualized as alternate black and white stripes.

Adsorption-desorption isotherms of calcined MSNs showed a typical curve for mesoporous silica (see Supporting Information), which consisted in an adsorption step at intermediate $P / P_{0}$ value (0.1-0.3). Narrow BJH pore distribution and absence of a hysteresis loop within this interval suggested the existence of uniform cylindrical mesopores (pore diameter of $2.10 \mathrm{~nm}$, pore volume of $0.26 \mathrm{~cm}^{3} \mathrm{~g}^{-1}$, calculated on the adsorption branch of the isotherm). Pore diameter was estimated by analyzing the TEM images that agreed with this value. After applying the BET model, a value of $1195 \mathrm{~m}^{2} \mathrm{~g}^{-1}$ was obtained for the total specific surface. The $\mathrm{N}_{2}$ adsorptiondesorption isotherm of solid S1 was typical of mesoporous systems with filled mesopores, and both the pore volume $\left(0.036 \mathrm{~cm}^{3} \mathrm{~g}^{-1}\right)$ and the specific surface area $\left(66 \mathrm{~m}^{2} \mathrm{~g}^{-1}\right)$ drastically diminished (see Supporting Information). This reduction in the BET surface, compared with that of the starting MSNs, was attributed to loading pores with safranin $\mathrm{O}$ and surface functionalization with aminopropyl moieties.

Calcined MSNs showed a negative zeta potential of $-11.90 \mathrm{mV}$ due to the silanolate groups, whereas $\mathbf{S 1}$ had a positive zeta potential $(3.02 \mathrm{mV})$ due to the presence of the positively charged safranin $\mathrm{O}$ (in the inner of the pores) and aminopropyl moieties (grafted onto the external surface of the nanoparticles). Finally, a marked reduction in the value of zeta potential $(-7.92 \mathrm{mV})$ was observed for S1-apMUC1 nanoparticles ascribed to pore capping with the negatively charged MUC1 aptamer.

Dealing with controlled release studies, it was observed that S1-apMUC displayed a poor safranin O release (ca. 10\% in the first 30 min and reached 20\% after $60 \mathrm{~min}$ ) in the absence of DNAse I (see Figure 3). However when the enzyme was present, a remarkable fast safranin O 
delivery took place (ca. $90 \%$ of the total amount released was found after ca. 30 min). The observed payload release was directly related with the DNAse I-induced hydrolysis of the MUC1 aptamer that allowed pore opening and dye delivery.

After conducting studies on the effective safranin O release from S1-apMUC1 in the presence of DNAse I, our next goal was to prove the possible use of these aptamer-capped nanoparticles as delivery system in cell models. First, cell viability studies using S1-apMUC1 nanoparticles at different concentrations were carried out by the WST-1 assays. S1-apMUC1 nanoparticles were non-toxic for MDA-MB-231 and MCF-10-A cells at concentration up to $200 \mu \mathrm{g} / \mathrm{mL}$ after 24 and $48 \mathrm{~h}$ of incubation (see Supporting Information). Moreover, confocal microscopy analyses were used to evaluate whether the nanoparticles were internalized in MDA-MB-231 cells by tracking rhodamine associated fluorescence in S-RhB-MUC1 nanoparticles. A dotted pattern of a rhodamine fluorescent signal associated with intracellular vesicles was observed (Figure 4, central panel), which suggests the internalization of nanoparticles. Moreover, the cells were marked with Lysotracker green DND-26, and co-localization of the nanoparticles with lysosomes was confirmed via the presence of a yellow signal in merged images (Figure 4 right panel).

Next, the uptake of S1-apMUC1 nanoparticles by MDA-MB-231 (which expresses high levels of glycoprotein MUC1 in its membrane) and MCF-10-A (which showed low levels of MUC1) cancer cells was studied (Figure 5). MDA-MB-231 cells internalized the S1-apMUC1 nanoparticles more efficiently than the MCF-10-A cells. In fact a strong red fluorescence of the released safranin $\mathrm{O}$ was observed in the cytoplasm for the MDA-MB-231 cells, whereas the signal in the MCF-10-A cells was significantly lower under the same conditions (see Figure 5A and C). These differences could be explained by a greater internalization of S1-apMUC1 in the MDA-MB-231 cells, which supports the specific targeting of the nanoparticle mediated by 
MUC1. Quantification of the fluorescence associated with safranin O was determined for each treatment (see also Figure 5D). A very weak safranin O emission for the MCF-10 cells treated with the S1-apMUC1 nanoparticles was observed. In contrast, a marked safranin O associated fluorescence (4-fold enhancement compared to that obtained for the MCF-10-A cells) was found for MDA-MB-231 cells treated with S1-apMUC1.

The key role played by MUC1 aptamer in the preferential internalization of S1-apMUC1 nanoparticles by MDA-MB-231 cells was assessed by testing the cellular uptake of solid S1-ap (loaded with safranin $\mathrm{O}$ and capped with a scrambled DNA sequence). As could be seen in Figure 5B negligible fluorescence associated with safranin O was observed in MDA-MB-31 cells incubated with S1-ap nanoparticles. Besides, this low safranin O emission when MDA-MB-31 cells were treated with S1-ap nanoparticles, clearly indicated that differences observed with S1apMUC1 under similar conditions are not due to different endocytosis ratios but most likely ascribed to the higher overexpression of MUC1 receptor in MDA-MB-31 cells.

Once demonstrated the role played by the MUC1 aptamer in the enhancement of the internalization of S1-apMUC1, our next purpose was to test the possible use of these nanoparticles as drug delivery carriers. For this purpose, doxorubicin was selected as cargo for the preparation of solid S2-apMUC1. Doxorubicin is employed in the treatment of various types of cancer. However, the non-specific cellular internalization of this drug is associated to major secondary effects (such as cardio- and nephrotoxicity). ${ }^{57}$ Loading doxorubicin in nanoparticles has been reported to be an interesting strategy to decrease the unwanted secondary effects, thereby increasing the efficiency of this drug. ${ }^{58}$ Internalization and cargo delivery of S2apMUC1 were tested in MDA-MB-231 and MCF-10-A cells. Figure 6 shows viability studies of cells treated with the S2-apMUC1 nanoparticles A remarkably decrease in the viability of 
MDA-MB-231 cells, which overexpressed MUC1 glycoprotein, upon treatment with S2apMUC1 nanoparticles, was observed. This decrease is associated to doxorubicin release due to preferential uptake by MDA-MB-231 cells and subsequent hydrolysis of the MUC1 cap. In contrast, in the case the MCF-10-A cells (which lower expression of the MUC1 glycoprotein) the cell viability was ca. 80\% indicating a poor doxorubicin release inside these cells.

Then, S1-apMUC1 nanoparticles were labelled with ${ }^{99 \mathrm{~m}} \mathrm{Tc}$ and their targeting ability was studied in MDA-MB-231 tumor-bearing Balb/c mice. In vivo imaging using SPECT the MUC1positive tumor region showed strong signals due to the accumulation of S1-apMUC1-Tc nanoparticles at 90 min post-injection (Figure 7A). This is a remarkable result which revealed that the accumulation of S1-apMUC1-Tc nanoparticles in tumors was significantly larger compared with the bioaccumulation of the free MUC1 aptamer labeled with ${ }^{99 \mathrm{~m}} \mathrm{Tc}$ (vide infra). ${ }^{49-}$ ${ }^{51}$ Marked accumulation was also observed in the upper part of the image, which correlated with the injection site (retro-orbital). Figure 7B depicts the bioluminescence imaging that indicates the tumor position, which correlated with planar images; accumulation of the S1-apMUC1-Tc nanoparticles by the tumor, as observed by comparing bioluminescence (red and yellow spots in Figure 7B) and planar images. The high S1-apMUC1-Tc accumulation in the tumor was suggested to be partly due to the interaction of the MUC1 aptamer in the functionalized MSNs with the MUC1 glycoprotein overexpressed in the MDA-MB-231 cancer cells. This suggests that S1-apMUC1-Tc is a potential candidate for cancer diagnosis by imaging. Besides, SPECT images of kidneys, liver and tumor excised from the S1-apMUC1-Tc-treated mice after 120 min post-injection showed strong signals (see Supporting Information) indicating accumulation of S1-apMUC1-Tc nanoparticles in these organs. 
Bio-distribution profiles (Figure 8) of the S1-apMUC1-Tc nanoparticles showed a significant uptake of the nanodevice by tumoral lesions (ca. 20\% ID/g and 15\% ID). This result once again suggested the targeting abilities of the S1-apMUC1-Tc nanoparticles towards the MUC1 glycoprotein overexpressed in the MDA-MB-231 cancer cells. A certain uptake of the labeled nanoparticles by lungs and intestine was observed. These results were expected since the MUC1 glycoprotein ubiquitously spreads throughout the body, especially to intestine and lungs. However, accumulation in tumor was remarkably larger. Besides, the excellent uptake of the S1apMUC1-Tc nanoparticles by kidneys is a desirable feature since radioactive materials have to be excreted from the body quickly and efficiently. The activity observed in bladder is in accordance with the finding of nanoparticles in kidneys and indicated a non-reabsorption effect of the nanomaterial in kidneys. Another remarkable feature of the bio-distribution data is the low uptake percentage observed in the liver and spleen. This low uptake for these two organs suggested that the S1-apMUC1-Tc nanoparticles were able to avoid the mononuclear phagocytic system (MPS). This fact was corroborated by presence of radiation in blood, which suggested that nanoparticles have a certain affinity for blood proteins (e.g., albumin) and, consequently, a long-lasting circulation, which agreed with a certain signal in the heart. Finally, it is important to note the negligible uptake by the brain, which is quite a desirable feature for radiopharmaceutical materials and radioactive drugs.

Bio-distribution profiles of ${ }^{99 \mathrm{~m}} \mathrm{Tc}$ labeled MSNs (without the MUC1 aptamer) in healthy and MDA-MB-231 tumor-bearing Balb/c mice as negative and positive controls respectively were also obtained (see Supporting Information). ${ }^{99 \mathrm{~m}}$ Tc labeled MSNs accumulated in kidneys and liver in healthy mice. Besides, in MDA-MB-231 tumor-bearing Balb/c mice, bio-distribution profile showed accumulation of nanoparticles in kidneys, bladder, stomach and liver. However, 
the most remarkable feature of the positive control is the nearly negligible tumor accumulation of the ${ }^{99 m}$ Tc labeled MSNs. This strongly contrast with the results when using S1-apMUC1-Tc nanoparticles. This indicated the crucial role played by MUC1 aptamer in the observed tumor accumulation of S1-apMUC1-Tc. MUC1 aptamer acts not only as gatekeeper but also as targeting unit directing S1-apMUC1-Tc nanoparticles to MDA-MB-231 cells in an in vivo model.

It is noteworthy that the bio-distribution results obtained with the S1-apMUC1-Tc nanoparticles showed remarkable performance in terms of relative accumulation in tumors compared to other systems; e.g., several PET/SPECT nanoparticle-based materials (that involve, or not, aptamer bio-direction) or others based on radiolabeled MUC1 aptamers or antibodies, or when compared to other aptamer-based radio-diagnosis systems. For instance, it has been reported that MUC1 aptamers functionalized with a cyclen macrocycle and labeled with ${ }^{99 \mathrm{~m}} \mathrm{Tc}$ show minor tumor accumulation (0.01-0.12\% ID/g), with larger amounts located in liver and kidneys. ${ }^{49}$ Similarly, radiolabeled bare MSNs have been reported to display a relatively low accumulation of the injected dose in tumors $(5.4 \% \mathrm{ID} / \mathrm{g}) .{ }^{37}$ These results demonstrated that radiolabeling MUC1 aptamer-bearing MSNs offers remarkable performance in imaging terms compared with using the aptamer or MSNs alone. We believe that this approach is general and can be used to design other similar nanoparticles for imaging applications.

In summary, we have designed, synthesized and characterized MUC1 aptamer-capped MSNs able to preferentially release an entrapped cargo (safranin O and doxorubicin) in MDA-MB-231 cells that overexpress glycoprotein MUC1. Moreover, nanoparticles were also radiolabeled with ${ }^{99 m}$ Tc and used for bio-imaging applications. S1-apMUC1 nanoparticles showed poor cargo release in the absence of DNAse I, whereas marked safranin O delivery took place when the 
enzyme was present. Confocal microscopy studies revealed that the S1-apMUC1 nanoparticles were significantly uptaken by MDA-MB-231 cells and were able to deliver safranin $\mathrm{O}$, whereas a remarkably lower cargo delivery was found for control MCF-10-A cells. Besides, S2-apMUC1 nanoparticles were also preferentially internalized by MDA-MB-231 cells and a marked reduction in viability was observed related with the release of the entrapped doxorubicin. The nanoparticles labeled with the ${ }^{99 m}$ Tc radioisotope (S1-apMUC1-Tc) were used in the radioimaging studies on MDA-MB-231 tumor-bearing Balb/c mice. Remarkable tumor signaling and accumulation were observed. S1-apMUC1-Tc displayed well-enhanced tumor signaling when compared with other studies in which the MUC1 aptamer or the bare MSNs were also labeled

with ${ }^{99 \mathrm{~m}} \mathrm{Tc}$. These results indicated that the combination of MSNs capped with aptamers and labeled with radionuclides is a promising candidate for theranostic applications (delivery + imaging). We believe that the results shown herein open up a wide range of new possibilities to develop smart innovative drug delivery and diagnostic nanodevices based on combination of capped mesoporous hybrid materials and radiopharmaceuticals.

\section{ACKNOWLEDGEMENTS}

Ll. P. is grateful to the Universitat Politècnica de València for his grant. A.G-F. is grateful to the Spanish government for her FPU grant.

\section{REFERENCES}

1 Wilson M. Nanotechnology: Basic Science and Emerging Technologies. Chapman \& Hall/CRC 2002.

2 Sandhya G, Kannan V, Nandakumar K. Recent Advances in Nanomedicine: Applications in Diagnostic and Therapeutics. Adv. Nanomat. 2015;251-287. 
3 Rani V. Nanomedicine and its Applications. J. Chem. Pharm. Res. 2015;7:216-227.

4 Arias JL. Nanotechnology and Drug Delivery. Chapman \& Hall/CRC 2016.

5 Kita K, Dittrich C. Drug Delivery Vehicles with Improved Encapsulation Effciency:

Taking Advantage of Specific Drug-carrier Interactions. Expert Opin. Drug Deliv. 2011;8:329-342.

6 Du J, Lane LA, Nie S. Stimuli-responsive Nanoparticles for Targeting the Tumor Microenvironment. J. Control. Release 2015;219:205-214.

7 Slowing II, Trewyn BG, Giri S, Lin VSY. Mesoporous Silica Nanoparticles for Drug Delivery and Biosensing Applications. Adv. Funct. Mater. 2007;17:1225-1236.

8 Rurack K, Martínez-Mánez R. The Supramolecular Chemistry of Organic-Inorganic Hybrid Materials. Wiley-VCH Verlag, 2010.

9 Aznar E, Oroval M, Pascual L, Murguía JR, Martínez-Máñez R, Sancenón F. Gated Materials for On-Command Release of Guest Molecules. Chem. Rev. 2016;116:561-718.

10 Coll C, Bernardos A, Martínez-Máñez R, Sancenón F. Gated Silica Mesoporous Supports for Controlled Release and Signaling Applications. Acc. Chem. Res. 2013;46:339-349.

11 Sancenón F, Pascual Ll, Oroval M, Aznar E, Martínez-Máñez R. Gated Silica Mesoporous Materials in Sensing Applications. ChemOpen 2015;4:418-437.

12 Yang YW. Towards Biocompatible Nanovalves Based on Mesoporous Silica Nanoparticles. Med. Chem. Commun. 2011;2:1033-1049.

13 Agostini A, Mondragón L, Pascual Ll, Aznar E, Coll C, Martínez-Máñez R, Sancenón F, Soto J, Marcos MD, Amorós P, Costero AM, Parra M, Gil S. Design of Enzyme-Mediated Controlled Release Systems Based on Silica Mesoporous Supports Capped with EsterGlycol Groups. Langmuir 2012;28:14766-14776. 
14 Agostini A, Mondragón L, Bernardos A, Martínez-Máñez R, Marcos MD, Sancenón F, Soto J, Costero AM, Manguan-García C, Perona R, Moreno-Torres M, Aparicio-Sanchis R, Murguía JR. Targeted Cargo Delivery in Senescent Cells Using Capped Mesoporous Silica Nanoparticles. Angew. Chem. Int. Ed. 2012;51:10556-10560.

15 Zhu YF, Meng WJ, Hanagata N. Cytosine-Phosphodiester-Guanine Oligodeoxynucleotide (CpG ODN)-Capped Hollow Mesoporous Silica Particles for Enzyme-Triggered Drug Delivery. Dalton Trans. 2011;40:10203-10208.

16 Coll C, Mondragón L, Martínez-Máñez R, Sancenón F, Marcos MD, Soto J, Amorós P, Pérez-Payá E. Enzyme-Mediated Controlled Release Systems by Anchoring Peptide Sequences on Mesoporous Silica Supports. Angew. Chem. Int. Ed. 2011;50:2138-2140.

17 Mas N, Agostini A, Mondragón L, Bernardos A, Sancenón F, Marcos MD, MartínezMáñez R, Costero AM, Gil S, Merino-Sanjuan M, Amorós P, Orzáez M, Pérez-Payá E. Enzyme-Responsive Silica Mesoporous Supports Capped with Azopyridinium Salts for Controlled Delivery Applications. Chem. Eur. J. 2013;19:1346-1356.

18 Patel K, Angelos S, Dichtel WR, Coskun A, Yang YW, Zink JI, Stoddart JF. Enzymeresponsive Snap-top Covered Silica Nanocontainers. J. Am. Chem. Soc. 2008;130:23822383.

19 Schlossbauer A, Kecht J, Bein T. Bitoin-Avidin as a Protease Responsive Cap System for Controlled Guest Release from Colloidal Mesoporous Silica. Angew. Chem. Int. Ed. 2009;48:3092-3095.

20 Thornton PD, Heise A. Highly Specific Dual Enzyme-mediated Payload Release from Peptide-coated Silica Particles. J. Am. Chem. Soc. 2010;132:2024-2028.

21 Wang F, Liu X, Willner I. DNA Switches: From Principles to Applications. Angew. 
Chem. Int. Ed. 2015;54:1098-1129.

22 Lu CH, Willner B, Willner I. DNA Nanotechnology: From Sensing and DNA Machines to Drug-Delivery Systems. ACS Nano 2013;7:8320-8332.

23 Oroval M, Climent E, Coll C, Eritja R, Aviñó A, Marcos MD, Sancenón F, MartínezMáñez R, Amorós P. An Aptamer-Gated Silica Mesoporous Material for Thrombin Detection. Chem. Commun. 2013;49:5480-5482.

24 Li ZH, Liu Z, Yin ML, Yang XJ, Yuan QH, Ren JS, Qu XG. Aptamer-Capped Multifunctional Mesoporous Strontium Hydroxyapatite Nanovehicle for Cancer-CellResponsive Drug Delivery and Imaging. Biomacromolecules 2012;13:4257-4263.

25 Hernandez FJ, Hernandez LI, Pinto A, Schafer T, Ozalp VC. Targeting Cancer Cells with Controlled Release Nanocapsules Based on a Single Aptamer. Chem. Commun. 2013;49:1285-1287.

26 Jayasena SD. Aptamers: An Emerging Class of Molecules That Rival Antibodies in Diagnostics. Clin. Chem. 1999;45:1628-1650.

27 Ferreira CSM, Missailidis S. Aptamer-Based Therapeutics and Their Potential in Radiopharmaceutical Design. Brazilian Arch. Biol. Technol. 2007;50:63-76.

29 Chrastina A, Schnitzer JE. Iodine-125 Radiolabeling of Silver Nanoparticles for in Vivo SPECT Imaging. Int. J. Nanomedicine 2010;5:653-659.

30 Guo Z, Gao M, Zhang D, Li Y, Song M, Zhuang R, Su X, Chen G, Liu T, Liu P, Wu H, Du J, Zhang X. Simultaneous SPECT Imaging of Multi-Targets to Assist in Identifying Hepatic Lesions. Sci. Rep. 2016;6:28812.

31 Santos-Oliveira R, Albernaz M, Szwed M, Iscaife A, Leite K, Junqueira M, Bernardes E, da Silva E, Tavares MI, Sarcinelli M. Nanoradiopharmaceuticals for Breast Cancer 
Imaging: Development, Characterization, and Imaging in Inducted Animals. Onco. Targets. Ther. 2016;9:5847-5854.

32 Ligiero TB, Cerqueira-Coutinho C, de Souza Albernaz M, Szwed M, Bernardes ES, Wasserman MAV, Santos-Oliveira R. Diagnosing Gastrointestinal Stromal Tumours by Single Photon Emission Computed Tomography Using Nano-Radiopharmaceuticals Based on Bevacizumab Monoclonal Antibody. Biomed. Phys. Eng. Express 2016;2:45017.

33 Carmo FS, Missailidis S, Al-Malki Y, Al-Qahtani M, Santos-Oliveira R. Development of Aptamer Anti-MUC1 Labeled with Na-22 and Ga-68 as a Positron Emission Tomography Radiopharmaceutical. Lat. Am. J. Pharm. Am. J. Pharm. 2016;35:2056-2063.

34 Zhang X. Cell-SELEX Aptamer for Highly Specific Radionuclide Molecular Imaging of Glioblastoma in Vivo. PLoS One 2014;9:e90752.

35 Varmira K, Hosseinimehr SJ, Noaparast Z, Abedi SM. A HER2-Targeted RNA Aptamer Molecule Labeled with ${ }^{99 m}$ Tc for Single-Photon Imaging in Malignant Tumors. Nucl. Med. Biol. 2013;40:980-986.

36 Jacobson O, Yan X, Niu G, Weiss ID, Ma Y, Szajek LP, Shen B, Kiesewetter DO, Chen X. PET Imaging of Tenascin-C with a Radiolabeled Single-Stranded DNA Aptamer. J. Nucl. Med. 2015;56:616-621.

37 Chen F, Hong H, Goel S, Graves SA, Orbay H, Ehlerding EB, Shi S, Theuer CP, Nickles RJ, Cai W. In Vivo Tumor Vasculature Targeting of CuS@MSN Based Theranostic Nanomedicine. ACS Nano 2015;9:3926-3934.

38 Chen F, Hong H, Shi S, Goel S, Valdovinos HF, Hernandez R, Theuer CP, Barnhart TE, Cai W. Engineering of Hollow Mesoporous Silica Nanoparticles for Remarkably Enhanced Tumor Active Targeting Efficacy. Sci. Rep. 2014;4:5080. 
39 Chen F, Hong H, Zhang Y, Valdovinos HF, Shi S, Kwon GS, Theuer CP, Barnhart TE, Cai W. In Vivo Tunor Targeting and Image-guided Drug Delivery with Antobodyconjugated, Radiolabeled Mesoporous Silica Nanoparticles. ACS Nano 2013;7:9027-9039.

40 Chen F, Goel S, Valdovinos HF, Luo H, Hernandez R, Barnhart TE, Cai W. In Vivo Integrity and Biological Fate of Chelator-free Zirconium-89-labeled Mesoporous Silica Nanoparticles. ACS Nano 2015;9:7950-7959.

41 Denk C, Svatunek D, Mairinger S, Stanek J, Filip T, Matscheko D, Kuntner C, Wanek T, Mikula H. Design, Synthesis and Evaluation of Low-molecular-weight ${ }^{11}$ C-labeled Tetrazine for Pretargeted PET Imaging Applying Bioorthogonal in Vivo Click Chemistry. Bioconjugate Chem. 2016;27:1707-1712.

42 Wuillemin MA, Stuber WT, Fox T, Reber MJ, Brühwiler D, Alberto R, Braband HA. Novel ${ }^{99 m}$ Tc Labelling Strategy for the Development of Silica Based Particles for Medical Applications. Dalton Trans. 2014;43:4260-4263.

43 de Sousa Azevedo RC, Ferreira Soares DC, de Sousa RG, Barros de Sousa EM. Multifunctional Nanostructured Materials Applied in Controlled Radiopharmaceuticals Release. J. Biomater. Nanotechnol. 2012;3:163-168.

44 Cheng SH, Yu D, Tsai HM, Morshed RA, Kanojia D, Lo LW, Leoni L, Govind Y, Zhang L, Aboody KS, Lesniak MS, Chen CT, Balyasnikova IV. Dynamic in Vivo SPECT Imaging of Neutral Stem Cells Functionalized with Radiolabeled Nanoparticles for Tracking of Glioblastoma. J. Nucl. Med. 2016;57:279-284.

45 Branco de Barros AL, de Oliveira Ferraz KS, Soares Dantas TC, Ferreira Andrade G, Cardoso VN, Barros de Sousa EM. Synthesis, Characterization, and Bio-distribution Studies of ${ }^{99 m}$ Tc-labeled SBA-16 Mesoporous Silica Nanoparticles. Mater. Sci. Eng. C, 
Mater. Biol. Appl. 2015;56:181-188.

46 Apostolopoulos V, Vasso S, Gargosky SE. MUC1 (CD227): A Multi-tasked Molecule. Cell. Mol. Life Sci. 2015;72:4475-4500.

47 Walker JM. Mucins Methods and Protocols, Vol 842. McGuckin MA, Thornton DJ, Eds.; Methods in Molecular Biology; Humana Press: Totowa, NJ, 2012; Vol. 842.

48 Stroopinsky D, Kufe D, Avigan D. MUC1 in Hematological Malignances. Leuk. Lymphoma 2016;57:2489-2498.

49 Da Pieve C, Blackshaw E, Missailidis S, Perkins AC. PEGylation and Bio-distribution of an Anti-MUC1 Aptamer in MCF-7 Tumor-Bearing Mice. Bioconjug. Chem. 2012;23:1377-1381.

50 Da Pieve C, Perkins AC, Missailidis S. Anti-MUC1 Aptamers: Radiolabelling with Tc99m and Bio-distribution in MCF-7 Tumour-Bearing Mice. Nucl. Med. Biol. 2009;36:703-710.

51 Da Pieve C, Perkins A, Missailidis S. Development of Anti MUC1 DNA Aptamers for the Imaging of Breast Cancer. Eur. J. Cancer Suppl. 2008;6:30-31.

52 Jo H, Her J, Ban C. Dual Aptamer-Functionalized Silica Nanoparticles for the Highly Sensitive Detection of Breast Cancer. Biosens. Bioelectron. 2015;71:129-136.

53 Kresge CT, Leonowicz ME, Roth WJ, Vartuli JS, Beck JS. Ordered Mesoporous Molecular Sieves Synthesized by a Liquid-crystal Template Mechanism. Nature 1992;359:710-712.

54 Barrett EP, Joyner LG, Halenda PP. The Determination of Pore Volume and Area Distributions in Porous Substances. I. Computations from Nitrogen Isotherms. J. Am. Chem. Soc. 1951;73:373-380. 
55 Brunauer S, Emmet PH, Teller E. Adsorption of Gases in Multimolecular Layers. J. Am. Chem. Soc. 1938;60:309-319.

56 Kobayashi Y. Applications of Nuclear Technique to Biological Sciences Labeled Compounds, Radioactive Tracers and X-Ray Tomography. Curr. Top. Med. Chem. 2016;16:2694-2702.

57 Fornari FA, Randolph JK, Yalowich JC, Ritke MK, Gewirtz DA. Interference by Doxirubicin with DNA Unwinding in MCF-7 Breast Tumor Cells. Mol. Pharmacol. 1994;45:649-656

58 de la Torre C, Mondragón L, Coll C, Sancenón F, Marcos MD, Martínez-Máñez R, Amorós P, Pérez-Payá E, Orzaez M. Cathepsin-B Induced Controlled Release from Peptide-Capped Mesoporous Silica Nanoparticles. Chem. Eur. J. 2014;20:15309-15314. 